\title{
On the Mistranslation of Cultural Words in the English Versions of Sun Tzu's Art of War
}

\author{
Jianchuan Zhou ${ }^{1}$ \\ ${ }^{1}$ School of Foreign Languages, Nantong University, China \\ Correspondence: Jianchuan Zhou, School of Foreign Languages, Nantong University, China. E-mail: \\ sudazjc@163.com
}

Received: May 4, 2015 Accepted: May 29, 2015 Online Published: July 6, 2015

doi:10.5539/ass.v11n21p300 URL: http://dx.doi.org/10.5539/ass.v11n21p300

\begin{abstract}
Sun Tzu's Art of War is originally a book of military science, and its influence has transcended military field and found its way into politics, business, and diplomacy. This book has been translated into English by both Chinese and western scholars. However, it is noticeable that there are many mistranslations in these versions for various reasons. This paper holds three reasons for the mistranslation at large, namely, the translator's compromise to the patrons; misinterpretation of the source text; and the translator's cultural incompetence. Emphasis is laid on the factors concerning the mistranslation of cultural words(or culture-loaded words).Examples are given to illustrate the importance of the translator's cultural competency without which the translation would be incomprehensible and unacceptable. In a global exchange context, more attention to cultural differences may contribute to cultural communication and progress.
\end{abstract}

Keywords: culture-loaded words, cultural words, mistranslation, Sun Tzu's Art of War

\section{Introduction}

Masterpiece as it is, Sun Tzu's Art of War has invited both praise and criticism from the very beginning since its translated versions appeared. Its introduction to Europe began in 1782, when Joseph Amiot, a French Jesuit Father living in China, translated it into French. It was not a good translation because, according to Dr. Giles(1993), "It contains a great deal that Sun Tzu did not write, and very little indeed of what he did." The first English version was published in 1905 in Tokyo by Capt. E. F. Calthrop. However, there were many problems in this version. Omissions were common and difficult passages were distorted. In 1908, a new edition of Capt. Calthrop's was published in London. It was an improvement on the first, with many omissions filled up and mistakes corrected. But new errors were still found in this version. It was not until 1910 when a valuable edition translated by Dr. Giles was published. This edition was highly commemorated, and it established much of the groundwork for later translators. Besides, it was scholarly and presented readers an incredible amount of background informationt. Different from his predecessors, Lionel Giles exerted much energy on compiling voluminous endnotes and footnotes. It seemed that he wanted to produce a definitive edition superior to the previous versions and perhaps something that would become a standard translation. True, this was the case for almost 50 years. But in 1963 another English version by Samuel Griffith was published, which was valued as an equal to Giles' translation. Though this translation was more lucid than Dr. Giles', it lacked Giles' copious and informative notes.

Chinese scholars also showed great interest in translating this great book. In 1936, Zheng Lin published the first English version translated by Chinese scholars. Zheng's version corrected some mistakes in Giles' version and set a good example for future Chinese scholars. From 1949 to 1979, no influential English versions were made because of ideological reasons; however, two generals, Guo Huaruo and Tao Hanzhang, made very careful notes and put this ancient classic into modern Chinese. It is said that during the Gulf War American navy soldiers were required to take a military book at hand which was translated from General Tao's modern Chinese version. When China carried out the reform and opening policy in 1979, the translation of this book stepped into a new era. Many Chinese scholars published their English versions, for example, Lin Wusun, Yuan Shibin, and Luo Zhiye to name but a few. Mistranslations are also easy to be found in the versions made by Chinese scholars, and the most common ones are caused by a misunderstanding of the original text. 
A general review of the translation history of Sun Tzu's Art of War keeps us wondering why mistranslations still exit in different editions after so many years of improvement. Many reasons may lead to mistranslation, especially when the original text is written in ancient Chinese even modern Chinese readers have difficulty in reading and understanding. Besides, some translators like Captain Calthrop translated not from the original Chinese text but from a Japanese version which surely increased the possibility of mistranslation. One major mistake these translators committed in common is that they all translated Sun Tzu's Art of War with little understanding of Sun Tzu's competitive system. More often than not, careful readers find these versions vague and full of contradictions. They tend to think that these problems come from Sun Tzu, which is not doing justice to him. Literal translation is employed in many versions, but translators have not spent the time necessary to grasp Sun Tzu's philosophy of war that provides the context. Examples of the most common mistranslations are listed in the following part.

\section{Common Mistranslation}

\subsection{Examples of Common Mistranslation}

As far as the translation of the title "SunZiBingFa" is concerned, the most common rendition, Sun Tzu's Art of War, is something of a mistranslation. It is used in this paper not because it is the best translation but because it is the most widespread. The last two Chinese characters in the title are BingFa whose literal meaning is "military methods" or "army procedures", and the most adequate English translation would be the single word "strategy". The word "strategy" comes from ancient Greek, meaning literally "the thinking of a general". The concept of strategy covers all the essential elements of Sun Tzu's work. The fact that the book is about strategy, not war, explains why its methods apply so well in a wide range of human activities, including achieving success in business and overcoming challenges in life. However, Sun Tzu's Art of War sounds more academic and formal than the single word "strategy" does. Thus, the replacement of "Sun Tzu's Strategy" with "Sun Tzu's Art of War" seems justifiable.

Generally speaking, patrons, especially publishers and booksellers, care much about how many books they can sell, so circulation is their first concern. The best way to catch the eyes of potential buyers is to give books a conspicuous or even sensational title. In order to fulfill patrons' requirements, the translator has to make some adjustments even at the expense of distorting the original. This practice contributes a lot to deliberate mistranslation.

Another kind of mistranslation is those full of contradictions and confusing expressions. Because most translated books are Chinese-English editions, this paper uses the latest Roger T, Ames' version published in 2012 when the original text is cited for the sake of clarity.

Example 1: WeiShiYiQue (Ames, 2012)

Translation: Leave a way of escape to a surrounded enemy. (Yuan, 1998)

The translation of this sentence arouses much suspicion in readers because many translators do not bother to make a helpful explanation. For example, Lin Wusun's translation (2004) is "in surrounding the enemy, leave him an escape route", and Roger Ames' translation (2000) is "in surrounding the enemy, leave him a way out". A careful reader may wonder that why there should be an escape route or a way out for the enemy if they have been surrounded. The real purpose in leaving an outlet is to let the enemy see the possibility of escape and prevent them from fighting desperately so as to reduce the casualties when the final attack is launched. To make this sentence understandable, it is not only necessary but also indispensable to translate it in an explanatory way; otherwise the readers will have difficulty in understanding. For this sentence, Giles' version (1993) is more acceptable and comprehensible. "When you surround an army, leave an outlet free. This does not mean that the enemy is to be allowed to escape. The object is to make him believe that there is a road to safety, and thus prevent him fighting with the courage of despair."

Sun Tzu's Art of War is written in ancient Chinese which is quite different from modern Chinese in many respects. A good translation can only be achieved by a correct understanding of the original text which puts a high demand on the translator's competency in ancient Chinese. In some cases, mistranslation is made owing to an incorrect understanding of the source text.

Example 2: FuYongBingZhiFa, QuanGuoWeiShang, PoGuoCiZhi; QuanJunWeiShang, PoJunCiZhi. (MouGongDiSan) (Ames, 2012)

Translation: Generally in war, the best policy is to take the enemy state whole and intact; to destroy it is not. To have the enemy's army surrender in its entirety is better than to crush it. (Lin, 2004) 
In Sun Tzu's opinion, unity is of uttermost importance. He believes it is unity rather than quantity that forms the competitive strength of a nation. Much of the theme is elaborated by Sun Tzu in Chapter 3. What Sun Tzu means is that using your military forces in a united manner is the best way. If you make a false interpretation of this theme, chances are that you will never understand what Sun Tzu is demonstrating in this sentence.

Another reason for mistranslation is the translator's cultural incompetency. Translators without the knowledge of another culture usually apply common sense to interpret the original text which sometimes leads to mistranslation.

Example 3: TianZhe: YinYang, HanShu, ShiZhiYe. (Ames, 2012)

Translation: What is heaven? The heaven means day and night, cold and heat, and the sequence of the Seasons. (Luo, 1996)

The phrase "YinYang" which appears two times in Sun Tzu's Art of War is derived from Taoism. It is translated as "day and night" in many versions. As a matter of fact, "YinYang" means the two opposing principles in nature, the former feminine and negative, the latter masculine and positive. The philosophical marrow of "YinYang" is: everything has two sides which are in a continuous motion. These two sides keep breaking the old balance and seeking for a new one. Although "YinYang" has the meaning like "day and night", its connotation goes far beyond this. For example, afternoon is also called "YangZhongZhiYin" during the day time, while the first period of night (before 12 o'clock p.m.) is called "YinZhongZhiYang". The simple translation "day and night" fails to distinguish this difference completely. Furthermore, Sun Tzu's Art of War is a book of both military and philosophical values. The philosophical phrase "YinYang" does not have an equivalent expression in the English language. A useful way to deal with the translation of such cultural words is to translate in terms of its Chinese pronunciation like "gongfu" and "dazibao". Meanwhile, a footnote should be carefully added.

\subsection{Causes for Mistranslation}

In the above examples, mistranslation is mainly caused by three factors, namely, the translator's compromise to the patrons; misinterpretation of the source text; and the translator's lack of knowledge of the source language's culture. In this paper, the last one is elaborated. Different from common mistranslation caused by the translators' linguistic incompetence or carelessness, mistranslation of cultural words is correct on the grammatical level but incomprehensible and ambiguous for the readers.

Although every nation has its unique culture with distinctive history, ways of life, traditions, and customs, there are also many overlaps or similarities between cultures which make cross-cultural communication possible. Admittedly, it is very likely that a translator will commit errors in his translation if he is not frequently exposed to the foreign language's culture or familiar with the cultural differences. When translating foreign cultural words, a translator may be easily affected by his native culture deeply rooted in his mind. Knowledge acquired from his life experience in the native cultural background will sometimes lead to misinterpretations. Cultural mistranslation is prevalent in the circle of translation as a result of increasing cross-cultural exchanges and communication. It can be defined as a kind of under-translation which can not be noticed by literal translation, and a kind of imperfect translation when cultural elements have to be considered. Failure in the process of exchanges and communication between cultures urges translators to shift the focus of their research from linguistic factors to cultural ones.

\section{Mistranslation of Cultural Words}

As a founder of anthropology, E. B. Taylor (1871) made a classical definition of culture in his Primitive Culture: "Culture is that complex whole which includes knowledge, belief, art, morals, law, custom and other capabilities and habits acquired by man as a member of society." Taylor seems to lay his emphasis on the spiritual aspect of culture, yet the material aspect fails to get an equal importance in his definition. Later, Daniel Bates and Fred Plog (1990) proposed a more detailed and comprehensive definition: "Culture is a system of shared beliefs, values, customs, behaviors and artifacts that the members of a society use to cope with their world and with one another, and that are transmitted from generation to generation through learning." This definition covers almost every aspect of culture, paying equal attention to spiritual as well as material components of culture.

Based on the above two authoritative definitions of culture, four sub-systems can be classified in the anthropological sense. The first sub-system is techno-economic system which includes ecology, means of production, exchange and distribution of goods, crafts, technology and science and artifact. The second one is social system which includes social classes and groups, kinship system, politics and law, education, sports and entertainment, customs and general history. The third one is linguistic system which includes phonology and graphemes, morphology and syntax, semantics and pragmatics. The forth one is ideational system which 
includes cosmology, religion, magic and witchcraft, folklore, artistic creations as images, values, cognitive focus and thinking patterns, and ideology.

Examples of the mistranslated cultural words from all the above four sub-systems can be found in the English versions; however, it is beyond the ability of this paper to make a comprehensive study on this topic. Thus, examples are chosen from three catalogues, namely, ecology, religion, and syntax.

\subsection{Mistranslation Related to Ecology}

Cultural entities always exist in a certain region and inevitably reflect some ecological features which can be embodied by the language. Ignoring these differences caused by ecological elements, a translator will sooner or later commit a mistake. For example, ancient Chinese depended heavily on farming to survive, and they hoped for good weather to bring them a harvest. Naturally, there are many words and expressions with "Tian(sky)" in Chinese. In some cases, we can get a satisfactory translation provided the Chinese "Tian" means "sky" or "weather" such as "TianGaoHuangDiYuan" and "KaoTianChiFan" which can be translated as "An emperor is as far away as sky" and "to depend on weather to live". In Sun Tzu's Art of War, "Tian" altogether appears 36 times. Take its first appearance in the book as an example:

Example 4: YiYueDao, ErYueTian. (Ames, 2012)

Translation: The first of the five criteria is the way (Tao), the second is climate. (Ames, 2012)

Literally, "weather", "climate" and "heaven" carry the meaning that "Tian" contains. However, a comprehensive understanding of "Tian" may be achieved by the explanation in the same paragraph: TianZhe, YinYang, HanShu, ShiZhiYe. Roger Ames's translation is: Climate is light and shadow, heat and hot, and the rotation of the seasons.

It is not difficult to find that "Tian" refers to all the conditions influenced by the changes in heaven. Weather means the state of atmosphere at a given time and place; climate means the meteorological conditions, including temperature, precipitation, and wind, which characteristically prevail in a particular region, thus it contradicts with "change of seasons". Therefore, they fail to convey the full meaning of "Tian" in this sentence. In fact, "Tian" can not be fully translated by one single word because it follows an explanatory sentence in the original text. However, "sky" may be acceptable for the reason that changes in weather and climate were observed by watching the sky in ancient times. It is probably because heaven also carries such denotation like paradise and gods which are familiar to westerners that some translators choose weather and climate whose meaning is more specific and ambiguity-free.

Cultural mistranslation of "Tian" is also seen in the rendering of "MouShiZaiRen, ChengShiZaiTian" quoted from one of the Four Most Classical Chinese Literary Works---The Dream of Red Mansions. The translation of this sentence is a frequently cited example much discussed by translation critics. Hawkes put it into "Man proposes. God disposes". The reason this version arouses much interest is that it gives readers a false impression that the speaker of this utterance, Lady Liu, is also a Christian. Presumably, the translator wanted to make it easier for the intended readers to understand by transcending the barriers between the two different cultures. The target readers may feel close to the version, but cultural factors in the original text is lost. In this sense, it is better to put it into "Man proposes. Heaven disposes" as what Yang Xianyi did in his version.

\subsection{Mistranslation Related to Religion}

Religion is the belief in god or gods. In the ancient times when our ancestors have to struggle for living and survival, they build temples or churches to worship the gods and pray for blessings. With the passage of time, the temple which is supposed to be the place where religious rituals are held has changed its original function and turned into a place where emperors offer sacrifices to gods and hold meetings with high officials. Let's take a look at the translation of "Miao (temple)".

Example 5: FuWeiZhanErMiaoSuanShengZhe, DeSuanDuoYe. (Ames, 2012)

Translation: Now the general who wins a battle makes many calculations in his temple ere the battle is fought. (Giles, 1993)

The Chinese sentence seems clear in meaning, and many translators put "Miao" into "temple" in their translation. In fact, Chinese "Miao" does not evoke the same image as English temple does. Temple refers to "a building dedicated to religious ceremonies or worship" in the Webster Dictionary. The readers may wonder that why the prewar military meeting is not held in the court where a king summons his generals, but in the temple where religious ceremonies are held. In fact, "Miao" does not equal temple in this sentence. In the Xinhua Dictionary, "Miao" also means "royal or imperial court". For example, "JuMiaoTangZhiGao, ZeYouQiMIn" (When serving 
the court, I am concerned about the people and their needs.) It happens that in order to pray for victory and blessing from gods, both ancient Chinese and westerners would hold some ceremonies in the temple before a military action is carried out. However, such ceremonies are held after the war decision and strategies have been made in the court by the king and his generals! Therefore, this mistranslation is largely due to the misinterpretation of "Miao", although it has the same meaning as temple in most cases.

Another mistranslation that has to be mentioned in this sentence is "Suan". Etymologically, "Suan" is an ancient Chinese calculating tool made of wood, bamboo or bone which looks like a tablet. Later, it is applied to military field to indicate the military conditions. If one side possesses a favorable condition such as a favorable terrain, it will have one tablet of victory. If one side has more tablets than his enemy, it is much likely that this side will win the war. Thus, this sentence should be translated as "If the prewar military meeting held in the royal court indicates a victory, it is because this side has more tablets of victory than his enemy's".

\subsection{Mistranslation Related to Syntax}

Every language has its distinctive features, and effective communication cannot be achieved without taking such features into account. Therefore, an excellent translator will not impose one distinctive linguistic feature on another language, instead, he is ready to make adjustments and translate the message of the source text into the linguistic structure of the target language. In Translating Meaning, Nida (1983) points out that "the most important difference between Chinese and English is the difference of hypotaxis and parataxis", two terms first proposed by Wang Li (1951) in his Chinese Grammatical Theory. English highlights hypotaxis, an overt connecting relationship in which conjunction has to appear, while Chinese emphasizes parataxis, a covert connecting relationship in which conjunction does not necessarily appear. This difference often has some influence on the strategies employed by translators.

Example 6: ZhiBiZhiJi, BaiZhanBuDai. (Ames, 2012)

Translation 1: Know the enemy and know yourself; in a hundred battles, you will never be defeated. (Yuan, 1998)

Translation 2: If you know the enemy and know yourself, you need not fear the result of a hundred battles. (Giles, 1993)

The original sentence is a typical example of parataxis where no conjunction is used, yet the relationship between the two parts is obvious: the former becomes the condition of the latter. In the first translation, the translator put it into actually two sentences because semicolon functions as half a period which cut the relationship of the two parts. The second translation has a clear sentence structure and meaning, and realizes the discourse cohesion by employing "if" to introduce a conditional clause which clearly states the relationship of the two parts of the original text.

The difference of parataxis and hypotaxis makes it difficult for translators to realize discourse cohesion and convey to readers the intended meaning of the author. Halliday (1994) put forward two ways to realize discourse cohesion, that is, grammatical cohesion and lexical cohesion. Grammatical cohesion puts its emphasis on the use of coordinating and subordinating conjunctions to make a covert relationship overt. Another method frequently employed by grammatical cohesion is to combine loosely scattered sentences by using such linguistic forms as infinitives, participles and so on. The pervasive "flowing sentences" in Chinese especially deserve the translator's readiness to use such linguistic forms to make the translated version conform to the grammatical rules of English. Besides grammatical cohesion, lexical cohesion is another way to realize discourse cohesion. Lexical cohesion lays emphasis on the flexible repetition and collocation of certain lexis.

In a word, a translator should be aware of the difference of hypotaxis and parataxis and conscious enough not to impose one syntactic feature on the other. Furthermore, he should be ready to make flexible adjustments for the sake of discourse cohesion so as to avoid the mistranslation that an incompetent translator will sometimes produce.

\section{Conclusion}

Language is "not only the carrier of the information, but also the carrier of culture."(Samovar, 1981) Language is not only based on culture, but also reflects cultural realities. On the whole, language and culture have an inseparable relationship between each other. Translation, as a transfer of language, definitely cannot be separated from culture.

To sum up, some enlightenments can be obtained from this topic. First of all, the study of the mistranslation of cultural words will urge translators and researchers to study the similarities and differences between two cultures. 
In particular, some scholars put forward the concept of Contrastive Culturology. In addition, translation is actually a process of language fusion and cultural adjustment in which we import alien cultures and export native culture. We should have high awareness and sensitivity toward cultural differences and avoid or reduce the mistranslation of cultural words so as to deepen the mutual understanding of different nations and contribute to cultural communication and progress.

\section{References}

Ames, R. (2000). The Book of War. London: Random House.

Ames, R. (2012). Sun-Tzu: The Art of Warfare. Beijing: Zhong Hua Book, Co., Ltd.

Bates, D. G., \& Plog, F. (1990). Cultural Anthropology (3rd ed.). New York: McGraw-Hill.

Giles, L. (1993). The Art of War. Changsha: Hunan Publishing House.

Halliday, M. A. K. (1994). An Introduction to Functional Grammar. London: Edward Arnold.

Lin, W. (2004). Sun Tzu's Art of War. Beijing: Foreign Languages Press.

Luo, Z. (1996). Sun Tzu's Art of War. Beijing: China Translation \& Publishing Corporation.

Nida, E. A. (1983). Translating Meaning. San Diamas, California: English Language Institute.

Samovar, L. A. et al. (1981). Understanding of Intercultural Communication. Belmont: Wardsworth Publishing Company.

Taylor, E. B. (1871). Primitive Culture. London: John Murray.

Wang, L. (1951). Chinese Grammar Theory. Beijing: The Commercial Press.

Yuan, S. (1998). Sun Tzu's Art of War. Beijing: Foreign Language Teaching and Research Press.

\section{Copyrights}

Copyright for this article is retained by the author(s), with first publication rights granted to the journal.

This is an open-access article distributed under the terms and conditions of the Creative Commons Attribution license (http://creativecommons.org/licenses/by/3.0/). 